\title{
SUSO PINTOR
}

\section{December 26, 1964-April 02, 2019}

\section{Geoffrey Burnstock ${ }^{1}$}

Received: 8 May 2019 / Accepted: 16 May 2019 /Published online: 13 June 2019

(C) Springer Nature B.V. 2019

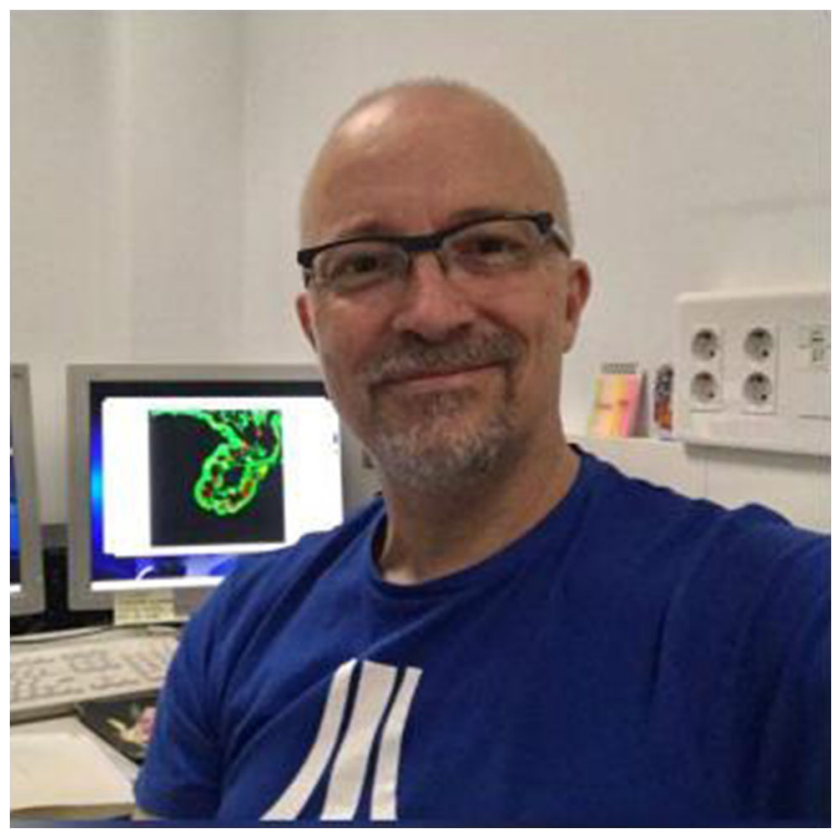

Jesús (Suso) Pintor was a major figure in the development of purinergic signalling, with important contributions in particular in both its role in the physiology and pathophysiology of the eye. It is very sad that he passed away at such a young age from pancreatic cancer and he will be much missed, not only as a scientist but also as a warm and giving human being.

Publisher's note Springer Nature remains neutral with regard to jurisdictional claims in published maps and institutional affiliations.

Geoffrey Burnstock

gburnstock@unimelb.edu.au

1 Department of Pharmacology and Therapeutics, The University of Melbourne, Melbourne, Victoria, Australia 